\title{
Discovery of Association Rules from University Admission System Data
}

\author{
Abdul Fattah Mashat \\ Faculty of Computing and Information Technology. King Abdulaziz University, Jeddah, Saudi Arabia \\ Email: asmashat@kau.edu.sa \\ Mohammed M. Fouad \\ Faculty of Computing and Information Technology. King Abdulaziz University, Jeddah, Saudi Arabia \\ Email: mmfouad@kau.edu.sa \\ Philip S. Yu \\ College of Engineering, University of Illinois, IL, USA \\ King Abdulaziz University, Jeddah, Saudi Arabia \\ Email: psyu@cs.uic.edu \\ Tarek F. Gharib \\ Faculty of Computing and Information Technology. King Abdulaziz University, Jeddah, Saudi Arabia \\ Email: tfgharib@kau.edu.sa
}

\begin{abstract}
Association rules discovery is one of the vital data mining techniques. Currently there is an increasing interest in data mining and educational systems, making educational data mining (EDM) as a new growing research community. In this paper, we present a model for association rules discovery from King Abdulaziz University (KAU) admission system data. The main objective is to extract the rules and relations between admission system attributes for better analysis. The model utilizes an apriori algorithm for association rule mining. Detailed analysis and interpretation of the experimental results is presented with respect to admission office perspective.
\end{abstract}

Index Terms-Educational Data Mining, Association Rules Discovery, University Admission System.

\section{INTRODUCTION}

Data mining aims at the discovery of useful information from large collection of data. Recently, there are increasing research interests in using data mining in education. This newly emerging field, called Educational Data Mining (EDM), concerns with developing methods that discover knowledge from data originating from educational environments [1].

Data mining techniques can discover useful information that can be used in formative evaluation to assist educators establish a pedagogical basis for decisions when designing or modifying an environment or teaching approach. The application of data mining in educational systems is an iterative cycle of hypothesis formation, testing, and refinement. As we can see in Fig. 1 , educators and academics responsible are in charge of designing, planning, building and maintaining the educational systems. Different data mining techniques can be applied in order to discover useful knowledge that helps to improve both the academic and management processes [2].

Association rule mining is one of the major data mining techniques that interested in finding strong relationships and correlation among items in transactional databases. It can be employed in many areas including market analysis, decision support systems and financial forecast. An association rule has two measures: support and confidence that represent its statistical significance [3]. The problem of mining association rule is to discover the implication relation among items such that the presence of some items implies the presence of other items in the same transaction.

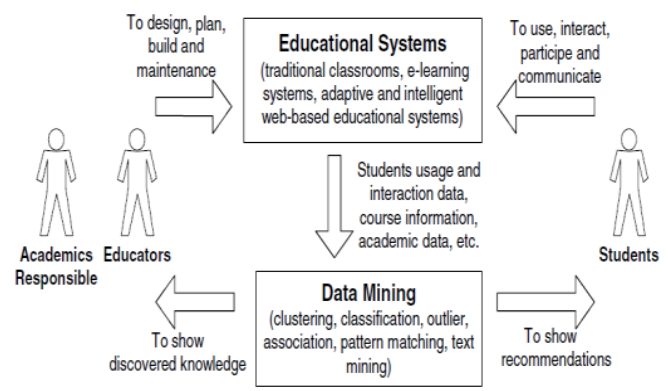

Figure 1. Data Mining Cycle in Educational System [2]

Mainly, all the proposed algorithms for association rules mining deals with transactional databases or market-basket data. These algorithms do not support relational databases naturally. To apply the same concepts and algorithms, relational database has to be converted to the transactional representation [4]. This requires the application of tedious conversion processes on large quantities of data before such algorithms can be applied as discussed with more details later in the paper. 
In this paper, we aim to use current association rules mining techniques to handle university admission system. The current system is modeled as a relational database that require some preprocessing to be suitable for mining algorithms of association rules. We aim to help the admission office better understand the nature of the system and the parameters that affect the decision making policy for accepting or rejecting the incoming students' applications.

The rest of this paper is organized into five sections. In section 2, the related work is presented. Section 3 contains, with brief details, the proposed association rules discovery model. In section 4 , experimental results are stated and analyzed with respect to model results and admission system perspective. Finally, the conclusions of this work are presented in Section 5.

\section{RELATED WORK}

Recently, some research studies were proposed to address the usage of data mining techniques in education especially in association rule mining.

Feng et al. Proposed a data mining model for university enrollment system. Their model contains two tasks; the first one was SOM clustering to group the Chinese provinces according to registration rate, first wish rate and Gross Domestic Product (GDP). The second task was to extract association rules from students' collage choice, interests and the relevance of specialties to aid the management in making subspecialty enrollment scheme and sub-specialty enrollment propaganda [1].

Buldua et al. used association rules to discover the relation between the courses and the failed students. They apply the apriori algorithm on the data of students of Istanbul Eyup I.M.K.B. Vocational Commerce High School in which a list of failed courses was assigned to each student. Their model showed some important notes about the students' performance in numerical courses to be adapted in the future [5].

Encheva et al. presented in [6] an association rule mining model to find correlations among students' preliminary knowledge. Their target was to decide which specific knowledge students do not possess in order to start a new course successfully or to proceed with another section in a current subject. For each student, a list of test results was marked to evaluate the presented model. They utilized the same model to find the correlations among students' preliminary knowledge in mathematics and their abilities to solve linear algebra related problems [7].

Abdullah et al. proposed a new measurement called Critical Relative Support (CRS) to mine critical least association rules from an educational context [8]. Least association rules are the association rules that consist of the least item. These rules are very important and critical since they can be used to detect the infrequent events and exceptional cases. The same authors also proposed a model to extract high correlation association rules. Their main objective was to examine enrollment data of omputer science students to find if this major matched with the students' field interests or not [9].

Recently, Kumar et al. used association rules mining in discovering the factors that affect postgraduate study and assessment in Haryana University, India. They used data for some courses taught for postgraduate students to measure the students' performance based on some factors like course instructor behavior, time schedule, curriculum design and students' interests [10].

\section{ASSOCIATION RULES DISCOVERY}

The association rules mining task are interested in extracting relations and correlation between items in market-basket data. In this format, the data contains several records called transactions, where each transaction is composed of some items as in Table I.

TABLE I. Transactional Database Example

\begin{tabular}{|c|c|}
\hline ID & Items \\
\hline 1 & $\mathrm{~A}, \mathrm{~B}, \mathrm{D}, \mathrm{E}$ \\
\hline 2 & $\mathrm{~B}, \mathrm{C}, \mathrm{E}$ \\
\hline 3 & $\mathrm{~A}, \mathrm{~B}, \mathrm{D}, \mathrm{E}$ \\
\hline 4 & $\mathrm{~A}, \mathrm{~B}, \mathrm{C}, \mathrm{E}$ \\
\hline 5 & $\mathrm{~A}, \mathrm{~B}, \mathrm{C}, \mathrm{D}, \mathrm{E}$ \\
\hline 6 & $\mathrm{~B}, \mathrm{C}, \mathrm{D}$ \\
\hline
\end{tabular}

The problem arises here is how to use the same algorithms to handle traditional relational databases where each record is composed of field values.

The association rules are represented as LHS $\rightarrow$ RHS, which means if the items in the LHS occurred then we can find the items in the RHS, which are called Boolean association rules. For example, a rule Tea $\rightarrow$ Sugar means that customers who bought tea tends to buy sugar also.

To determine the strength of an association rule, two measures are used; support and confidence. The support is the percentage of the database transactions that hold this rule and confidence measures the statistical significance of a rule. Consider rule $\mathrm{A} \rightarrow \mathrm{B}$, the confidence of this rule can be calculated using (1).

$\operatorname{confidence}(A \rightarrow B)=\frac{\operatorname{support}(A \cup B)}{\operatorname{support}(A)}$

There are two main steps to generate association rules:

1. Find all frequent itemsets in the database.

2. Generate association rules from frequent itemsets.

Finding all frequent itemsets is considered the main and challenging step of association rules discovery because it is computationally expensive. In other hand, generating association rules are straightforward step as illustrated later in this section.

\section{A. KAU Admission System}

King Abdulaziz University (KAU) admission system in the Kingdom of Saudi Arabia (KSA) is a complex decision process that goes beyond simply matching test scores and admission requirements because of many 
reasons. First, the university has many branches in KSA for both division male and female students. Second, there are huge numbers of applicants each year, which needs a complex selection criterion that depends on the high school study type, grades and applicant region/city.

In this paper, we are provided with samples from KAU system database that represent applicant student information and his/her status of being rejected or accepted to be enrolled in the university in three consecutive years (2010, 2011 and 2012). The database contains about $83 \mathrm{~K}$ records, while each record represents an instance with 4 attributes and one class attribute that represents application status. Table II shows detailed information about each attribute in this database [11].

TABLE II Summary of Database Attributes

\begin{tabular}{|c|c|}
\hline Attribute & Possible values \\
\hline $\begin{array}{l}\text { Students' Gender } \\
(\mathrm{G})\end{array}$ & $\begin{array}{ll}\text { - } & \text { Male }(\mathrm{M}) \\
\text { - } & \text { Female }(\mathrm{F})\end{array}$ \\
\hline $\begin{array}{c}\text { High School Study } \\
\text { Type (HT) }\end{array}$ & $\begin{array}{ll}\text { - } & \text { Scientific Study } \\
& \left(\mathrm{HT} \_S\right) \\
\text { - } & \text { Literature Study } \\
& \left(\mathrm{HT} \_L\right) \\
\text { - } & \text { Unknown (HT_U) }\end{array}$ \\
\hline $\begin{array}{c}\text { High School Grade } \\
\text { (HG) }\end{array}$ & $\begin{array}{l}\text { - } \mathrm{A}=\text { mark } \geq 85 \\
\text { - } \mathrm{B}=75 \geq \text { mark }>85 \\
\text { - } \mathrm{C}=65 \geq \text { mark }>75 \\
\text { - } \mathrm{D}=50 \geq \text { mark }>65\end{array}$ \\
\hline Area (A) & $\begin{array}{l}\text { Code for student's region } \\
\text { city }\end{array}$ \\
\hline $\begin{array}{l}\text { Application Status } \\
\text { (S) }\end{array}$ & $\begin{array}{l}\text { - Accepted } \\
\text { - Rejected }\end{array}$ \\
\hline
\end{tabular}

\section{B. Preprocessing}

The aim of the preprocessing step is to convert input database from its relational, tabular format into a transactional database format. In this process we simply assign some code for the possible values of each field, and then apply this coding scheme on the table to convert each record into a set of items as in marketbasket databases. Table III shows the coding scheme related to the possible values for each attribute in the admission database.

TABLE III Conversion Coding Scheme

\begin{tabular}{|c|l|}
\hline Attribute & \multicolumn{1}{|c|}{ Coding Scheme } \\
\hline Students' Gender (G) & $\bullet$ Male (GM) \\
& $\bullet$ Female (GF) \\
\hline High School Study & $\bullet$ Scientific Study (TS) \\
Type (HT) & $\bullet$ Literature Study (TL) \\
& $\bullet$ Unknown/Missing (TU) \\
\hline High School Grade & $\bullet$ A => HA \\
(HG) & $\bullet$ B => HB \\
& $\bullet$ C => HC \\
& $\bullet$ D => HD \\
\hline Area (A) & Axxxx (xxxx is area code) \\
\hline Application Status (S) & $\bullet$ Accepted (SA) \\
& $\bullet$ Rejected (SR) \\
\hline
\end{tabular}

Copyright @ 2013 MECS
Tables IV and V contain example records from input database and its equivalent transactions using the above coding scheme.

TABLE IV. Example Input Database

\begin{tabular}{|c|c|c|c|c|}
\hline $\mathbf{G}$ & HT & HG & A & S \\
\hline M & HT_S & A & 1007 & Accepted \\
\hline F & HT_L & B & 1004 & Rejected \\
\hline F & HT_S & D & 1004 & Accepted \\
\hline M & HT_U & B & 1005 & Rejected \\
\hline
\end{tabular}

TABLE V. Equivalent Transactional Database

\begin{tabular}{|c|c|}
\hline ID & Items \\
\hline 1 & GM, HS, HA, A1007, SA \\
\hline 2 & GF, HL, HB, A1004, SR \\
\hline 3 & GF, HS, HD, A1004, SA \\
\hline 4 & GM, HU, HB, A1005, SR \\
\hline
\end{tabular}

As illustrated in the earlier, each record is transformed into a set of items based on the values of its fields. For example, the first record is for student with male gender, scientific study in high school, obtained a grade 'A', from area with code 'A1003' and accepted status. This record is transformed to transaction $\{\mathrm{GM}, \mathrm{HS}, \mathrm{HA}$, A1007 and SA\} respectively.

\section{Apriori Algorithm}

The process of mining association rules consists of two steps: First, find all the frequent itemsets and secondly, generate the association rules from discovering frequent itemsets. The Apriori algorithm is the most well known algorithms for finding the frequent itemsets with candidate generation [12]. It is used for mining frequent itemsets for Boolean association rules. Many variations of the Apriori algorithm have been proposed that focus on improving the efficiency of the original algorithm.

The support of an itemset $\mathrm{A}$ is the percentage of transactions in the database that contain A. An itemset is frequent if the number of occurrences of that item is greater than or equal to a minimum support threshold min_supp.

Apriori algorithm starts by scanning the database to find all the items and count their support as candidates of size 1 (i.e. $\mathrm{C}_{1}$ ) and removes infrequent items (count < mis_supp).

To generate candidates of size $\mathrm{k}+1$, frequent itemsets from the previous pass are joined as $C_{k+1}=F_{k} \times F_{k}$. To improve the efficiency of the level-wise generation of frequent itemsets, an important property called the Apriori property is used to reduce the search space.

The Apriori property is based on the following observation. If an itemset $\mathrm{S}$ does not satisfy the minimum support threshold, min_supp, then $\mathrm{S}$ is not frequent. If an item $\mathrm{A}$ is added to the itemset $\mathrm{S}$, then the resulting itemset (i.e. $S \cup\{A\}$ ) Cannot occur more frequently than $\mathrm{S}$ and will be not frequent too [3]. 
So, the basic idea of the Apriori algorithm is to generate candidate itemsets of a particular size and then scan the database to count these to see if they are frequent. The candidates $\left(\mathrm{C}_{\mathrm{k}}\right)$, of size $\mathrm{k}$, are counted and only the frequent ones $\left(\mathrm{F}_{\mathrm{k}}\right)$ are used to generate candidates for the next pass candidates $\left(\mathrm{C}_{\mathrm{k}+1}\right)$ until no frequent itemsets found as stated in the Apriori property.

For example, consider the dataset shown in table I. We need to apply the Apriori algorithm to find frequent itemsets with minimum support $60 \%(0.6 * 6=3.6)$, which means that the itemset is frequent if it is occurring in at least 4 transactions. Figure 2 shows the detailed algorithm steps.

The algorithm starts by scanning the items in the database and counting their support to remove the infrequent ones. To generate candidate- 2 itemsets, the algorithm joins the items in F1 as they all share the same prefix class. The join operation between two itemsets $\mathrm{L}_{\mathrm{i}}$ and $L_{j}$ of size $k$ is performed as follows: $L_{i}=\left\{a_{1}, a_{2}, \ldots\right.$, $\left.\mathrm{a}_{\mathrm{k}-1}, \mathrm{a}_{\mathrm{k}}\right\}$ and $\mathrm{L}_{\mathrm{j}}=\left\{\mathrm{a}_{1}, \mathrm{a}_{2}, \ldots, \mathrm{a}_{\mathrm{k}-1}, \mathrm{~b}_{\mathrm{k}}\right\}$ can be joined to generate $\mathrm{L}_{\mathrm{ij}}=\left\{\left\{\mathrm{a}_{1}, \mathrm{a}_{2}, \ldots, \mathrm{a}_{\mathrm{k}-1}, \mathrm{a}_{\mathrm{k}}, \mathrm{b}_{\mathrm{k}}\right\}\right.$ of size $\mathrm{k}+1$. They must share the prefix class which is the itemset of $\mathrm{k}-1$ items (i.e. $\left\{a_{1}, a_{2}, \ldots, a_{k-1}\right\}$ in this case), otherwise they cannot be joined.

For example, in $F_{2}$, only $\{A B\}$ has prefix class $\{A\}$, so it cannot be joined with other $F_{2}$ itemsets. On the other hand, $\{B C\},\{B D\}$ and $\{B E\}$ have the same prefix class (which is $\{B\}$ ) so we can join each two of them to produce $\mathrm{C}_{3}=\{\mathrm{BCD}\},\{\mathrm{BCE}\}$ and $\{\mathrm{BDE}\}$. The algorithm stops at this iteration because there are no $F_{3}$ itemsets.

\section{Generating Association Rules}

Once the frequent itemsets have been found from the transaction database, it is straightforward to generate the association rules for them. These rules must satisfy both minimum support and minimum confidence thresholds. Since the rules are generated from frequent itemsets, each one automatically satisfies minimum support.

The association rules are generated as follows:

1. For each frequent itemset $\mathrm{F}$, generate all the nonempty subsets of $F$.

2. For every non-empty subset $s$ of F, output the rule " $s \rightarrow(F-s)$ " if its confidence is greater than or equal min_conf threshold.

As an example, the frequent itemsets in Figure 2 will be used to generate output association rules as shown in with min_conf $=70 \% . \mathrm{F}_{1}$ itemsets are neglected because it contains only one item and will produce no rules. The generated rules that satisfy min_conf threshold are highlighted in Table VI.

$\Rightarrow=$\begin{tabular}{|c|c|}
\hline$F_{1}$ & count \\
\hline$\{A\}$ & 4 \\
\hline$\{B\}$ & 6 \\
\hline$\{C\}$ & 4 \\
\hline$\{D\}$ & 4 \\
\hline$\{E\}$ & 5 \\
\hline
\end{tabular}

Pass 2: $\mathrm{C}_{2}=\mathrm{F}_{1} \times \mathrm{F}_{1}$

\begin{tabular}{|c|}
\hline $\mathrm{C}_{2}$ \\
\hline$\{\mathrm{AB}\}$ \\
\hline$\{\mathrm{AC}\}$ \\
\hline$\{\mathrm{AD}\}$ \\
\hline$\{\mathrm{AE}\}$ \\
\hline$\{\mathrm{BC}\}$ \\
\hline$\{\mathrm{BD}\}$ \\
\hline$\{\mathrm{BE}\}$ \\
\hline$\{\mathrm{CD}\}$ \\
\hline$\{\mathrm{CE}\}$ \\
\hline$\{\mathrm{DE}\}$ \\
\hline
\end{tabular}

\begin{tabular}{|c|c|}
\hline $\mathrm{C}_{2}$ & count \\
\hline$\{\mathrm{AB}\}$ & 4 \\
\hline$\{\mathrm{AC}\}$ & 2 \\
\hline$\{\mathrm{AD}\}$ & 3 \\
\hline$\{\mathrm{AE}\}$ & 3 \\
\hline$\{\mathrm{BC}\}$ & 4 \\
\hline$\{\mathrm{BD}\}$ & 4 \\
\hline$\{\mathrm{BE}\}$ & 5 \\
\hline$\{\mathrm{CD}\}$ & 2 \\
\hline$\{\mathrm{CE}\}$ & 3 \\
\hline$\{\mathrm{DE}\}$ & 3 \\
\hline
\end{tabular}

$==>\quad$\begin{tabular}{|c|c|}
\hline$F_{2}$ & count \\
\hline$\{\mathrm{AB}\}$ & 4 \\
\hline$\{\mathrm{BC}\}$ & 4 \\
\hline$\{\mathrm{BD}\}$ & 4 \\
\hline$\{\mathrm{BE}\}$ & 5 \\
\hline
\end{tabular}

Pass 3: $\mathrm{C}_{3}=\mathrm{F}_{2} \times \mathrm{F}_{2}$

\begin{tabular}{|c|}
\hline $\mathrm{C}_{3}$ \\
\hline$\{\mathrm{BCD}\}$ \\
\hline$\{\mathrm{BCE}\}$ \\
\hline$\{\mathrm{BDE}\}$ \\
\hline
\end{tabular}

Scan
DB
$==>$

\begin{tabular}{|c|c|}
\hline $\mathrm{C}_{3}$ & count \\
\hline$\{\mathrm{BCD}\}$ & 2 \\
\hline$\{\mathrm{BCE}\}$ & 3 \\
\hline$\{\mathrm{BDE}\}$ & 3 \\
\hline
\end{tabular}

$==$\begin{tabular}{|l|l|}
\hline $\mathrm{F}_{3}$ & count \\
\hline\{\} & \\
\hline
\end{tabular}

Figure 2. Example of Apriori Algorithm 
TABLE VI. Example Input Database

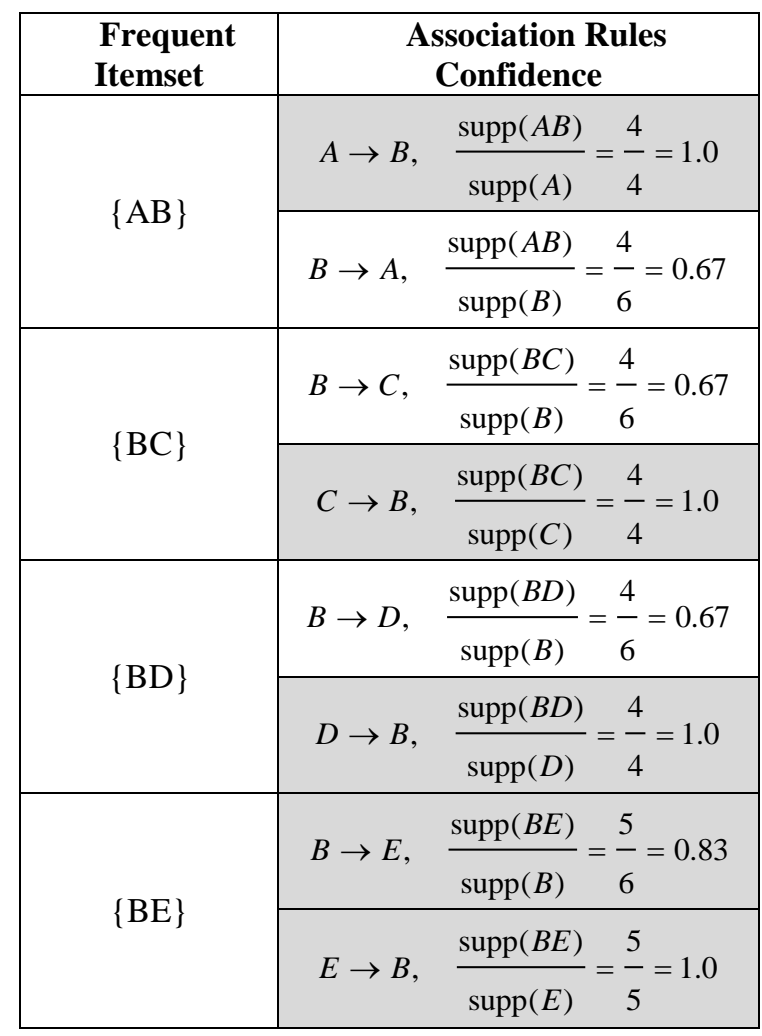

\section{RESULTS AND DISCUSSION}

\section{A. Frequent Itemset}

The entire database is processed to extract the association rules between the values of the input attributes. First, Apriori algorithm was applied to find all the frequent itemsets in the database with minimum support threshold min_supp $=40 \%$. There are 11 frequent itemsets as shown in Table VII with their support value.

TABLE VII. Frequent Itemsets

\begin{tabular}{|c|c|}
\hline Itemset & Supp. (\%) \\
\hline$\{\mathrm{A} 1007\}$ & 44.3 \\
\hline$\{\mathrm{GF}\}$ & 61.0 \\
\hline$\{\mathrm{HA}\}$ & 70.3 \\
\hline$\{\mathrm{TL}\}$ & 77.6 \\
\hline$\{\mathrm{SA}\}$ & 45.6 \\
\hline$\{\mathrm{SR}\}$ & 54.4 \\
\hline$\{\mathrm{GF}, \mathrm{HA}\}$ & 40.0 \\
\hline$\{\mathrm{GF}, \mathrm{TL}\}$ & 54.5 \\
\hline$\{\mathrm{HA}, \mathrm{SA}\}$ & 40.7 \\
\hline$\{\mathrm{HA}, \mathrm{TL}\}$ & 57.3 \\
\hline$\{\mathrm{TL}, \mathrm{SR}\}$ & 43.4 \\
\hline
\end{tabular}

We can notice that the majority of the applicants are females (about 61\%), obtained 'A' grade in their high school (about 70\%) and studied literature study (about $77 \%)$.
In spite of about $70 \%$ of the applicants holds ' $A$ ' grade in high school, only $40 \%$ of them were accepted to study in KAU, which means that the university accepts only the highest standard and very qualified students.

\section{B. General Association Rules}

As stated earlier, only size-2 frequent itemsets will be used to generate association rules. Table VIII shows the extracted association rules with min_supp $=40 \%$ and min_conf $=75 \%$ thresholds.

TABLE VIII. Generated Association Rules

\begin{tabular}{|c|c|c|}
\hline Rule & Supp. (\%) & Conf. (\%) \\
\hline $\mathrm{SA} \rightarrow \mathrm{HA}$ & 40.7 & 89.4 \\
\hline $\mathrm{SR} \rightarrow \mathrm{TL}$ & 43.4 & 79.7 \\
\hline $\mathrm{GF} \rightarrow \mathrm{TL}$ & 54.5 & 89.3 \\
\hline $\mathrm{HA} \rightarrow \mathrm{TL}$ & 57.3 & 81.5 \\
\hline
\end{tabular}

There are four extracted association rules that have confidence not less than $75 \%$, which means that they are very strong relations. From these rules, we can conclude the following:

1. The accepted students have a high school grade 'A' with $89.4 \%$ confidence.

2. The rejected students most likely were in literature study in their high school with $79.7 \%$ confidence.

3. The female students most likely were in literature study in their high school with $89.3 \%$ confidence.

4. Grade ' $A$ ' students most likely were in literature study in their high school with $81.5 \%$ confidence.

\section{Classification Rules Induction}

The database is classified into two classes with respect to application status. There are about $54.4 \%$ rejected (45K records) and $45.6 \%$ accepted (38K records) applications. We split the database is split into two parts based on the application status and apply the mining model separately to each part separately to find the relation between the values of the attributes and their class which gives a better understanding of the nature of the admission system.

TABLE VIII. "Rejected” Class - Association Rules

\begin{tabular}{|c|c|}
\hline Rule & Supp. (\%) \\
\hline $\mathrm{GF}, \mathrm{TL} \rightarrow \mathrm{SR}$ & 62.7 \\
\hline $\mathrm{GF} \rightarrow \mathrm{SR}$ & 70.8 \\
\hline $\mathrm{TL} \rightarrow \mathrm{SR}$ & 79.7 \\
\hline
\end{tabular}

Table IX shows the extracted association rules with thresholds min_supp $=60 \%$ in case of rejected students, we can notice that:

1. $\underline{62.7 \%}$ of the rejected students are females and studied literature study in high school.

2. $\underline{70.8 \%}$ of the rejected students are females. 
3. $\underline{79.7 \%}$ of the rejected students studied literature study in their high school.

TABLE X. "Accepted” Class - Association Rules

\begin{tabular}{|c|c|}
\hline Rule & Supp. (\%) \\
\hline $\mathrm{HA}, \mathrm{A} 1007 \rightarrow$ SA & 60.1 \\
\hline $\mathrm{A} 1007 \rightarrow$ SA & 67.8 \\
\hline $\mathrm{HA}, \mathrm{TL} \rightarrow \mathrm{SA}$ & 68.4 \\
\hline $\mathrm{TL} \rightarrow \mathrm{SA}$ & 75.2 \\
\hline $\mathrm{HA} \rightarrow \mathrm{SA}$ & 89.4 \\
\hline
\end{tabular}

Table $\mathrm{X}$ shows the extracted association rules with thresholds min_supp $=60 \%$ in case of accepted students, we can notice that:

1. $\underline{60.1 \%}$ of the accepted students are from 'Jeddah' city and obtained grade ' $\mathrm{A}$ ' in high school.

2. $67.8 \%$ of the accepted students are from 'Jeddah' city.

3. $68.4 \%$ of the accepted students studied literature study and obtained grade 'A' in high school.

4. $\underline{75.2 \%}$ of the accepted students studied literature study in high school.

5. $\underline{89.4 \%}$ of the accepted students obtained grade 'A' in high school.

\section{CONCLUSION}

In this paper, we presented an association rule discovery model to investigate and analyze KAU admission system database. The model discovered the relation students' data and their application status in the university system. Mainly, most of the accepted students are from 'Jeddah' city, obtained a grade ' $A$ ' in their literature study in high school. Also, most of the rejected students are female students that have literature study in their high school. This information is very important to the admission office in KAU because it enhances their perspective to the admission system and shows how to filter the applicants with respect to their record in high school.

Another important point discovered from this work that state the class of students that KAU seeks. In spite of about $70 \%$ of the applicants holds ' $A$ ' grade in high school, only $40 \%$ of them were accepted to study in KAU. In addition, KAU admission office can use this information in adopting some advertisement strategies in other cities in the kingdom or offer some scholarships to excellent students to join the university.

\section{REFERENCES}

[1] S. Feng, S. Zhou and Y. Liu, "Research on Data Mining in University Admissions Decisionmaking," International Journal of Advancements in Computing Technology, Vol. 3, no. 6, 176-186, 2011.

[2] C. Romero and S. Ventura, "Educational data mining: A survey from 1995 to 2005," Expert Systems with Applications, Vol. 33, 135-146, 2007. DOI:10.1016/j.eswa.2006.04.005
[3] J. Han and M. Kamber, Data Mining: Concepts and Techniques, Morgan Kaufmann, 2001.

[4] A. Alashqur, "Mining Association Rules: A Database Perspective," International Journal of Computer Science and Network Security (IJCSNS), Vol. 8, no. 12, 69-74, 2008.

[5] A. Buldua and K. Üçgün, "Data mining application on Students' data," Procedia Social and Behavioral Sciences 2, 5251-5259, 2010. DOI:10.1016/j.sbspro.2010.03.855

[6] S. Encheva and S. Tumin, "Application of Association Rules for Finding Correlation Among Students Preliminary Knowledge," Proceedings of the 3rd international conference on Cooperative Design, Visualization, and Engineering (CDVE'06), 303-310, 2006. DOI:10.1007/11863649_37

[7] S. Encheva and S. Tumin, "Application of Association Rules in Education," Proceedings of International Conference on Intelligent Computing (ICIC 2006), Kumming, China, 834-838, 2006. DOI:10.1007/978-3-540-37256-1_105

[8] A. Abdullah, T. Herawan, N. Ahmad and M.M. Deris, "Mining significant association rules from educational data using critical relative support approach," Procedia - Social and Behavioral Sciences 28, 97-101, 2011. DOI:10.1016/j.sbspro.2011.11.020

[9] A. Abdullah, T. Herawan, N. Ahmad and M.M. Deris, "Extracting highly positive association ules from students' enrollment data," Procedia - Social and Behavioral Sciences 28, 107-111, 2011. DOI:10.1016/j.sbspro.2011.11.022

[10] V. Kumar, A. Chadha, "Mining Association Rules in Student's Assessment Data," International Journal of Computer Science Issues, Vol. 9, no. 5, 211-216, 2012.

[11] A.M. Mashat, M.M. Fouad, P.S. Yu and T.F. Gharib, "Decision Tree Classification Model for University Admission System," International Journal of Advanced Computer Science and Applications, Vol. 3, no. 10, 17-21, 2012.

[12] M.H. Dunham, Data Mining: Introductory and Advanced Topics. Pearson Education Inc., 2003.

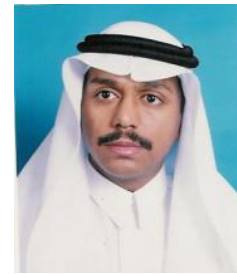

Dr. Abdul Fattah Suleman Mashat is the Dean of Faculty of Computing and Information Technology, King Abdulaziz University, Jeddah, Saudi Arabia. He received his Ph.D. degree in Distributed Multimedia Systems from the University of Leeds, UK in 1999. His research interests include Multimedia Systems, E- learning, computer networks, Ad-hoc and wireless networks, QoS Support for multimedia traffic, Modeling and simulation of computer networks. 


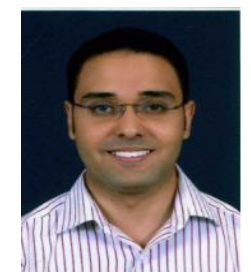

Mohammed M. Fouad finished his B.Sc and M.Sc. degree in computer science department, in the Faculty of Computer and Information Sciences, Ain Shams University, Egypt. He is currently a Ph.D. student in the same faculty and works as a lecturer in the Faculty of Computing and Information Technology, King Abdulaziz University, Saudi Arabia. His research interests are in the fields of data mining, text and web mining, association rules discovery, computer vision and image processing.

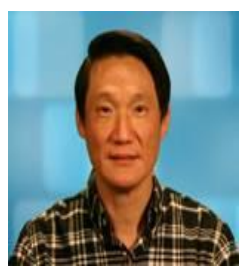

Philip S. Yu is a Professor in Computer Science at the University of Illinois at Chicago and also holds the Wexler Chair in Information Technology. Dr. Yu spent most of his career at IBM, where he was manager of the Software Tools and Techniques group at the Watson Research Center. His research interest is on big data, including data mining, data stream, database and privacy. He has published more than 730 papers in refereed journals and conferences. He holds or has applied for more than 250 US patents. Dr. $\mathrm{Yu}$ is a Fellow of the ACM and the IEEE. He is the Editor-in-Chief of ACM Transactions on Knowledge Discovery from Data. Dr. Yu received the B.S. Degree in E.E. from National Taiwan University, the M.S. and Ph.D. degrees in E.E. from Stanford University, and the M.B.A. degree from New York University.

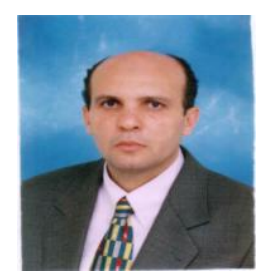

Tarek Fouad Gharib is a Professor of Information Systems in the Faculty of Computer and Information Sciences, Ain Shams University, Cairo, Egypt. He received his Ph.D. degree in Theoretical Physics from the University of Ain Shams. His research interests include data mining techniques, Bioinformatics, graph and sequential data mining and information retrieval. He has published over 30 papers on data mining. He received the National Science Foundation Award in 2001. Prof. Gharib is currently with Faculty of Computing and Information Technology, King Abdulaziz University, Saudi Arabia 